\title{
Pragmatic Perspectives of Hofstede's Organizational Dimensions in the Context of ICT-based Culture: Evidence from Public Universities in Pakistan
}

\author{
Prof Dr Muhammad Yousuf Sharjeel \\ Department of Education, SZABIST, Karachi \\ yousufsharjeel@hotmail.com
}

\author{
Shahzad Haider \\ VFM, Faculty of Education \\ LUAWMS, Uthal \\ Mehnaz Aslam \\ Department of Education \\ University of Turbat, Kech
}

\begin{abstract}
The present study aimed at analysis of dimensions of organizational culture of universities in Baluchistan. The study was carried out using quantitative research methodology with survey method of research and data collection. A total of $n=126$ students, faculty members and administrative staff members (48 students, 48 faculty members and 30 administrative staff members) participated in this study. The sample was drawn through a multi-stage sampling design. Data was collected through close-ended, self-reported five-option Likert scale type questionnaire adopted with minor modifications from Zeqiri and Alija (2016). Analysis of collected data was carried out through SPSS V 24. Samples were contacted through consent letters and emails. All possible ways of legal and ethical considerations were part of the study. The analysis of data showed that the organisational culture of universities is a combination of Hofstede's proposed dimensions of organizational culture.Universities tend to be effective and sustainable in their approaches but this is not so accros the country in the context of higher education teaching and non-teaching faculty members. Organizational culture of universities have inexperience dominance and the culture has openness towards newcomers. Rigidness towards deadlines is also an attribute of universities' organizational culture, but there are few relaxations and comforts in working enviornments as well. Universities are contributing in a positive way towards society and have realistice and pragmatic approach towards teaching and reearch. This study recommends a valueable consideration of employees' personal needs and problems. The study also suggests that middle managers (Deans, Head of Departments) should be trained in human pschychology and human resources management.
\end{abstract}

Key Words: Dimensions, Organizational Culture, Hofstede's Model, University Culture

\section{Introduction}

The term culture is also meant those sub-cultures that exist at organizational level. These sub-cultures (administrative, faculty and student sub-cultures) affect and influence the overall 
culture of the organization (Adams, 2014). The manners and the ways an organization's members value and believe and behave accordingly to accomplish and achieve organization's goals and objectives is called organizational culture (Zeqiri \& Alija , 2016). Understanding culture of an organization is significant in pursuit to evaluate what actually is happening in the organization, how it is being run and how it can be improved (Schein, 2010). Study of Beytekin, Yalçınkaya, and Karaoc, (2010) found it an element of great importance that can manipulate and influence the success of an organization. Organizational culture has emerged as a very important field of interest for scholars and researchers. This concept of culture has been studied in depth and in different setting and environments so that consistency and productivity in workplace can be improved and developed.

Success, attainment of organizational goals and performance of an organization is directed and guided by its culture specifically among IT professionals. It is important for educational organization such as universities as it helps universities to have effectual and efficient management practices (Beytekin, Yalcinkaya, \& Karakoc, 2010).Organizational culture of professionals using IT-based environment of work as a concept has an indefinite nature which has been explained differently by various scholars (Lu, Plewa, \& Ho, 2016; Sudarsanam \& Sorwar, 2010). Culture of any organization is deep rooted in beliefs, principles and expectations of employees and organization (Castro \& Martins, 2010). A cross-cultural research conducted by Geert Hofstede (1980) examined a large database of more than 10,00,00 employees of IBM. The data was gathered through questionnaires from 40 different countries and the analysis of data revealed differences in IT-based employees' value statements that Hofstede related to their national cultures and basic dilemma in societies.

Later in 1990, Hofstede compared organizational cultures of 10 various organizations based in Denmark and the Netherlands. The analysis of data found very little differences in values, but there were large differences in practices. The results of this research proposed the famous six dimensions of organizational culture. These dimensions are: i) Process-oriented dimension versus Result-oriented dimension, ii) Job-oriented dimension versus Employee-oriented dimension, iii) Parochial-oriented dimension versus Profession- oriented dimension, iv) Open-system dimension versus Close-system oriented dimension, v) Loose-control dimension versus Tight-control dimension and vi) Norm-oriented dimension versus Pragmatic dimension. The current study was set in the IT-based work environment in public sector universities in Balochistan. 
Hofstede (2011) defined dimensions as a conceptual manner by which complex and multifaceted truths and realities are divided into separate simple and elementary components and features. Hofstede's six-dimension model is the most influential model in the opinions of research scholars in management sciences. This model has laid down the basis of analysis of organizational culture and many scholars (Ansah, Louw , and Belso-Mart, 2019; Nazarian, Atkinson, and Greaves, 2014; Wendt , Euwena, and Emmerik, 2009; Scholten and Gomes, 2008; Soares, Farhangmehr, \& Shoham, 2007) have used these dimensions in both marketing and management researches despite drawbacks.In the similar context, the researchers used the model among IT professionals to assess its effectives in their work environemt in public sector universities Hsu, Tien, Lin, and Chang, (2015)argued that Hofstede's model is largely used as cultural framework.

In twenty-first century, universities have to change their role in accordance with the new challenges they have to face. Universities have been transformed from an IT-based hub to be associated with research and development. This phenomenon and pattern have been adopted and followed by higher education commissions in Pakistan too. Initial studies focused on showing and illustrating that universities have a different and unique culture in comparison to other organizations as far as use of IT is concerned. (Kezar \& Eckel, 2002). Bartell, (2003) argues that difference of background of employees of a university using communication strategies using stateof-the-art- technology characterizes the cultural diversity as well as discipline and order of the university. IT-based organizational culture of a university has its uniqueness as the organizational culture of university is rooted in the reality that any educational institution has a system of selforganizations that is established upon philosophies of knowledge, acquaintance, facts and erudition.

This self-organized system helps to establish an IT-based platform for various types of relationships like relationship among management, employees and student as these three are stakeholders of any educational institution. Students are the consumers of educational services that university provides. This service necessarily uses IT-based environment using modern devices, soft wares, client-based servers and other technological tools to stay connected and inform the students. This type of relationship is a kind of internal relationship while external relationship revolves around alumni, parents, future or potential students and employers. The other fact is the competition and partnership that any educational institution has with other institutions based on how fast and reliable their communication strategies are using Information and Communication 
Technology (ICT). For its very complex affinity and connections with organizational culture and dimensions, Hofstede's model makes its presence felt to examine it critically and pedagogically. It is imperative to study and analyze organizational culture of universities. (Vasyakin, Ivleva,, Pozharskaya, \& Shcherbakova, 2016). IT-based culture of a university is made up of norms, morals, ethics which the members of the university share. Goals and objectives of the university are represented and explicated through these shared norms, values and processes using technological devices.

In order to have an understanding of the culture of a university, analysis of the behavior and values of the members of the university is very crucial as these values and behaviors help to maintain a healthy mindset and foster eternal betterment (Folch \& Ion, 2009). Organizational culture of a university is developed and manifested in different ways hence it is a matter of concern that universities must not only describe or classify their culture, but they also be able to use it, adjust, modify or change it in accordance with environmental changes (Zeqiri \& Alija , 2016). Tierney and Lanford, (2017) argued that contemporary higher education is facing troubles as higher education institutes are engaged in multiple partnerships, having multiple initiatives and launching variety of programs to cop-up with the financial and social needs. Among all these partnerships and programmes, the use of ICT is ubiquitous.

\subsection{Statement of the Problem}

Caliskan and Zhu, (2019) argued that for last two decades, universities have undergone under stress and pressure as they have to adapt to changes in social, political, technological and cultural domains. They must be smart users of ICT and technological strategies. There is paucity of researches in this domain as there are limited studies available globally and locally that attempted to study a public university's organization's cultural dimensions with focus on ICT and electronic communication. Based on the research, it is pragmatic to investigate with the realism of contemporary universities in Baluchistan to probe the type of culture these universities present. It is also essential in the context to explore the dimensions of organizational culture in these public universities. The researchers carried out this study to find out the cultural dimensions of universities using IT-based solutions to the professional and academic issues and challenges. 


\section{2. $\quad$ Research Objectives and Questions}

$\checkmark$ To find out the perceptions of members of the universities about organization's cultural dimensions using IT-based work environment

$\checkmark$ To find out the preferences of members of universities towards organization's cultural dimensions using IT-based work environment

Keeping research objectives in view, the following questions were developed.

1. What characteristics of dimensions of organizational culture do public universities using ICT possess per the Hofstede's model?

2. How do the members of university culture (faculty, administrative staff and students) perceive organizational culture of their respective universities who use ICT?

\subsection{Hypotheses}

Following hypotheses were formulated to seek answers to the research questions:

$\mathrm{H}_{0} 1$ There is no substantial variance in dimensions of organizational culture among selected universities using ICT.

$\mathrm{H}_{0} 2$ There is no substantial variance of opinion about dimensions of organizational culture among students, faculty members and administrative staff members of the universities using ICT.

\subsection{Significance of the Study}

This study is expected to add new knowledge about cultural dimensions of universities using ICT in existing literature as there is paucity of literature on dimensions of organizational culture. There are studies available on finding impacts or effects and correlation of organizational culture on various variables such as organizational behavior, job satisfaction, performance etc. The results of the study on ICT-based work environment would be beneficial to university administrators and policy makers in shaping policy guidelines and operating procedures keeping in mind the dimensions of organizational culture of their universities. Thus findings of this study will be beneficial not only for IT-based research community, but these findings will help the institutions to improve their ICT-based communication culture and subsequently to take decisions for improved and better accomplishment of their goals and objectives. 


\subsection{Delimitations of the Study}

The focus of this study was analysis of dimensions of organizational culture with emphasis on ICT that exist in public universities in Baluchistan province of Pakistan. Due to its limitations, it must not be generalized beyond its scope at a larger scale as it is limited in various aspects of time, finances, resources, sample size, level of cooperation, technical support, access to procedures and other research protocols.

\section{Review of Literature}

\subsection{Organizational Culture and Use of ICT}

Attitudes, values, norms, expectations, beliefs, philosophies and ideologies mutually shared by members of an organization are referred as Organizational culture (Lund, 2003). It includes the process and patterns that are carried out by members of an organization in fulfillment of their assigned task as well as the social interactions within the groups of members using their devices and technological advancement for effective communication. Solomanidina, (2011) defines organizational culture as spiritual and societel domain of an organization. Organizational culture is shaped and moulded by various factors which can be material or non-material processes and phenomena that may by observeable and hidden. These processes or phenomena can be conciousely or unconciousely driven and these practices and spectacles define the beliefs, thoughts, morals, problem-solving methods and communicative configurations of employees of the company. These attributes are factors that drive any organization on the way to attainment. Hence it can be argued that processes and resources are the tools by which change and behavior is guided and directed while culture is thoughts, beliefs and assumptions (Coman \& Bonciu, 2016).

ICT-based culture of an organization is developed and molded over a long period of time. It is shown when employees develop cooperation and trust among themselves and learn from each other. Culture of an organization can also mould attitude of organization's people as well. (Rashid, Sambasivan, \& Johari, 2003). Organizational culture is therefore considered as basic assumptions that are mutually shared by the members (Schein, 1999). To understand and comprehend the dynamics of Hofstede's culture of an organization, in-depth and knowledge of organizational culture combined with mutual relationships of the members of the organization play a vital role. In addition, deep understanding of the culture and the relationship among employees of the organization using effective modes of communication and information play a significant part. An 
appropriate and befitting culture encourages people to be creative, inventive and disseminate their knowledge with their peers within the organization (Holsapple \& Joshi, 2001).

\subsection{Dimensions of Organizational Culture}

There are numerous definitions in various domains such as anthropology, sociology and business administration with respect to organizational culture. According to Schein, (2004), anthropologists define it as traditions, habits and formal procedures which are gradually developed within the society. It has been used as a term to systematically analyze the culture of an organization in 1970's and 1980's. In 1980's and 1990's, many researchers believed that this was the only key to success of the organization (Alvesson \& Sveningsson, 2016). It is challenging, multifaceted and hard to describe the notion of organizational culture. "The reason for this difficulty arises from the use of culture as a term in a wide and varied sense, as well as the fact that culture has a structure so deep that it cannot be easily observed" (Schabracq, 2007).While defining culture, it is obligatory to go deep and below the behavioral dimensions because it can disturb other aspects other than culture (Schein, 2010, p. 22). The understanding of methods to define the culture by the scholars while understanding and driving the meanings of culture is very important. It is equally important to know how this word is studied and extracted. (Ehrhart, Schneider, \& Macey, 2014).

\subsection{Organizational Culture of a University}

Universities are multifaceted societal entities or organizations with a distinguishing type of organizational culture which is shaped by the continuous interactions between academics, administrators, staff, students, and government (Jameson, 2011). They use many technologically advanced devices and machines to improve work efficiency. Here, the members of the university commonly share the basic assumptions, beliefs, norms and values (Salonda, 2008). It is mandatory for universities to be people-oriented organizations to create various services and standards for each and every task it performs as there are many stakeholders like academic staff, students, and administrative staff as well as local community, social and political activists. QAAs and the press (Caliskan and Zhu, 2019). Scholars and researchers argue that in this time of competition, university culture must be capable to develop effective communication and information exchange. Scholars have argued that to survive and prosper in this competitive era, university culture should be able to create effectual, productive, ingenious and dynamic organization using fast and reliable 
devices and machines. Kobylarek, (2017) studied and concluded that a university culture, in this rapid changing world should respect and regard the changes and innovations of science, communication technologies and culture that surround the university. In addition , a university, as a living organism, should uplift, evolve and develop such a unique culture that is able to hold all the stakeholders together. This is possible only through the use of ICT.

\subsection{Hofstede's Model of Organizational Culture}

2.4.1.Process-Oriented Dimension vs. Results-Oriented Dimension. As the label shows that this dimension is a comparison of process orientation and result orientation of organizations. A culture which is process dominated is normally a well-established and well-articulated system that emphasizes on technical and administrative routines. At the other hand, a result dominated or result oriented organizational culture aims at accomplishment of job and achievement of anticipated results.

2.4.2. Employee-Oriented Dimension vs. Job-Oriented Dimension. This dimension denotes organizational culture's preference concerning to employees or the job. In a culture that prefers employees, people of the culture have importance and organization takes responsibility of overall well-being of the employees. Blake and Mouton, (1964) have also discussed this dimension of organizational culture at individual manager's level. Organizations take care of personal problems and concerns of the members of the organization and take responsibility of employee's well-being.

2.4.3. Parochial Dimension vs. Professional Dimension. This dimension shows and denotes the preference of the members towards their identity and how they identify themselves. In an organization where culture is profession oriented, members of the organization enjoy being identified by their professional relevance. Members of parochial or hidebound culture assume that the values and norms of the organization conceal or hide their conduct and comportment not only during their duty hours, but on their home as well (Hofstede, 1997). 
2.4.4. Open-System Dimension vs. Closed-System Dimension. This dimension of the culture denotes how organization and people of the organization treat new people, new ideas and new trends. In open system dimension, both people of the organization and the organization itself are open welcoming new people, ideas and trends. In close system-oriented dimension, the organization and the people of the organization remain closed and do not accept the out-comers, new people, ideas and trends (Hofstede, 1997).

2.4.5. Loose-Control Dimension vs. Tight-Control Dimension. The dimension of control examines the inner structure of the organization. In organizations that prefer loose control, the employees have more autonomy. Different departments function without much collaboration and cooperation with each other and operate independently. On the other hand, employees in a unit with tight control feel their work environment is tight and narrow where supervisors and middle management know exactly what is to be done by the employees. Management in such a situation coordinates all the activities in accordance with a central work plan (Hofstede, 1997).

2.4.6. Normative Dimension vs. Pragmatic Dimension. This dimension of organizational culture represents the manners and ways that an organization uses to deal with its customers and environment. The organization that prefers normative way of dealings, organizational procedures and processes are of importance rather than chasing and achieving results whereas the organizational culture where people are more pragmatic and realistic, meeting needs of the customers, accomplishment of task and attainment of results are more important (Hofstede, 1997).

\subsection{Dimensional Use of ICT Culture in Universities}

2.5.1. Process-Oriented Dimension vs. Result-Oriented Dimension. The analysis reveals that employees of LUAWMS and BUITEMS think that the staffs of the university do not give maximum while performing their duties as mean score of responses is 2.86 and 2.98 respectively which is less than the average. On the other hand, employees of University of Baluchistan think otherwise as mean score to their responses is 3.02 which is merely above average. For the second statement which is related to result orientation, the scores of all three universities' employees are above 3 which shows that the employees of the universities are more focused towards attainment of results rather than focusing on processes.

2.5.2. Employee-Oriented Dimension vs. Job-Oriented Dimension. The results indicate that employees of all three universities think that their universities do not care about personal problems 
of their employees as the mean scores of responses are 3.86, 3.69 and 3.76 respectively with an overall mean score of 3.77. In response to the second statement which is related to working environment, the results are similar to first statement as means score for this statement are 4.02 (LUAWMS), 3.98 and 3.90 with an overall mean score of 3.97 which indicates that universities do not pay much attention towards working environment. It can be assumed that universities have a job-oriented dimension of organizational culture as well-being of employees is compromised. Responses to the third statement related to managerial issues versus operational issues, the mean scores are less than a neutral point of 3 . The mean scores of responses to this statement are 2.45 , 2.88 and 2.38 respectively with an overall mean score of 2.57 . The results indicate that the management of universities is keener to solve management issues and problems as compared to solving operational issues. It also indicates that the management is more interested in getting job done and they do not give a head to operations i.e. how the job is done.

2.5.3. Parochial Dimension vs. Professional Dimension. Analysis of data revealed that employees of the universities with an overall mean score of 2.44 and university-wise mean scores of 2.33 for LUAWMS, 2.76 and 2.44 for UoB and BUITEMS respectively do not agree to the statement that cooperation and collaboration among the departments of the university is at appropriate level. Employees also did not agree to the next statement which is related to implementation of changes with alignment to staff requirements with an overall mean score of 2.26. Here university-wise mean scores are also below the neutral score of 3 (2.17 for LUAWMS, 2.43 for UoB and 2.19 for BUITEMS). These results indicate that changes in university processes and procedures are implemented. With an overall mean score of 2.86 , employees do not agree to the statement that their management supports them in further promotion.

University-wise results are different as employees and students of LUAWMS and BUITEMS do not agree to the statement with a mean score of 2.62 and 2.81 respectively. However, responses from employees and students from $\mathrm{UoB}$ are different with a mean score of 3.14 and they show an agreement to the statement that their management supports them in further promotion. With an overall mean score of 3.83, the participants agreed to the statement that they get feedback from their supervisors with a university-wise mean scores of 3.79 for both LUAWMS and UoB and mean score of 3.90 for BUITEMS. For next statement to this dimension, with an overall mean score of 3.95, respondents of this research agreed to the statement that the supervisors are more interested in job in hand rather than the results. Based on the results to this orientation, it is 
concluded that the universities tend have parochial dimensions, but at the other hand there are evidences of professionalism as well.

2.5.4. Open-System Dimension vs. Closed-System Dimension. The analysis of the statements revealed that universities have openness towards job seekers and new comers. While responding to first statement, participants of this research, with a cumulative mean of 4.06 agreed that their organization is open and welcomes new staff and job seekers. The respondents also have an agreement over the second statement which describes that new staff quickly finds support in adaptation of working environment and team with an overall mean score of 3.61. On the other hand, with an overall mean score of 3.60, participants of the research agreed to this statement as well. Keeping the results in view, it is therefore concluded that all three universities have a system of openness, cooperation and collaboration among individuals.

2.5.5. Loose-Control Dimension vs. Tight-Control Dimension. With a cumulative mean score of 2.02, participants of this research did not agree to the statement that they always come late for meetings. This score interprets and indicates a tight organizational control whereas while responding to the next statement, the participants agreed to the statement with an overall mean score of 3.79 that they seldom mind the work costs. This interprets that there is somehow some flexibility available within the organizational cultures of the universities. The results show that there is balance in loose control and tight mechanism within an organizational culture.

2.5.6. Normative Dimension vs. Pragmatic Dimension. With an overall mean score of 2.04, participants of this research did not agree to the statement that their university does not contribute in society in a significant and positive way. While on the other hand, participants with a cumulative mean score of 3.36, show their agreement to the statement that the university they work for or study in has a pragmatic and realistic approach to handle the things. Hence keeping in view, the results of analysis of data, it can be concluded that all three universities have an organizational culture of pragmatic and realistic orientation and also it is argued on the basis of these results that all three universities are contributing in a significant, positive and constructive way in betterment of the society.

\section{Methodology}

The study was carried out using quantitative research methodology with survey method of research and data collection. A sample of $n=126$ students, faculty members and administrative 
staff (48 students, 48 faculty members and 30 administrative staff members) participated in this study. They all used IT-based work environment for teaching and learning. The sample was drawn through a multi-stage sampling design. Data was collected through close-ended, self-reported fiveoption Likert scale questionnaire adopted with minor modifications from Zeqiri and Alija (2016). A pilot testing was carried out to ensure the reliability of the questionnaire. Analysis of collected data was carried out through SPSS V 24.

\section{Data Analysis}

$\mathrm{H}_{0} 1$ There is no significant difference in dimensions of organizational culture among selected universities who use ICT in their work.

Table 1: Hypothesis 1 - One-way ANOVA

\begin{tabular}{|l|r|r|r|c|c|}
\hline \multicolumn{7}{|c|}{ ANOVA } \\
\hline & Sum of Squares & \multicolumn{1}{|c|}{ Df } & Mean Square & F & Sig. \\
\hline Between Groups & .177 & 2 & .089 & 1.195 & .306 \\
\hline Within Groups & 9.119 & 123 & .074 & & \\
\hline Total & 9.296 & 125 & & & \\
\hline
\end{tabular}

The results of one-way ANOVA indicate that there is no significant difference of dimensions of organizational culture among all three universities as two-tailed significance is $\mathrm{p}$ value $0.306>0.05$, a type I error alpha. We fail to reject the Ho and it is concluded that all three universities (LUAWMS, UoB and BUITEMS) have no significant difference in dimensions of organizational culture.

$\mathrm{H}_{0} 2$ There is no significant difference of perception about dimensions of organizational culture among students, faculty members and administrative staff members of the universities who use ICT.

Table 2: Hypothesis 2-One-way ANOVA

\begin{tabular}{|c|c|c|c|c|c|}
\hline \multicolumn{6}{|c|}{ ANOVA } \\
\hline OCD & & & & & \\
\hline & Sum of Squares & $\mathrm{df}$ & Mean Square & $\mathrm{F}$ & Sig. \\
\hline Between Groups & .431 & 2 & .215 & 2.988 & .054 \\
\hline
\end{tabular}




\begin{tabular}{|l|r|r|r|r|l|}
\hline Within Groups & 8.865 & 123 & .072 & \\
\hline Total & 9.296 & 125 & & & \\
\hline
\end{tabular}

The results of one-way ANOVA indicate that there is no significant difference of perception about dimensions of organizational culture among students, faculty members and administrative staff of all three universities as the two-tailed significance of P-value is $0.054>$ 0.05, a type I error alpha. Hence the null hypothesis is accepted and it is concluded that there is no significant difference of perception about dimensions of organizational culture among students, faculty members and administrative staff of all three universities (LUAWMS, UoB \& BUITEMS).

\section{Findings}

Results revealed that all three universities have a result-oriented organizational culture where processes and procedures are over-looked or compromised in order to get the desired results. These results support the findings of Zeqiri and Alija (2016) as they concluded with such results stating that the employees of university are more focused to achieve desired results. Getting a job done is preferable in all three universities as compared to giving preference to employees and their problems. Universities' management is keen to get job done at any cost and the management does not pay attention in solving process related issues. It is evident from the findings that the management does not care about employees' issues and problems. Employees are of the opinion that their personal issues and problems are not being considered by the management. These findings are in line with the findings of Zeqiri and Alija (2016), who concluded that staff members think that their management does not pay due attention to their personal problems and it is more focused to get job done.

Based on the results to this orientation, it is concluded that the universities tend to possess parochial dimensions, but at the other hand there are evidences of professionalism as well as there is a lack of cooperation among various departments of universities. Universities do not tend to implement changes in ICT unless in accordance with the requirements of staff, but at the other hand staff gets a regular feedback for their work from supervisors and supervisors are more focused towards job in hand rather than the consequences. These findings negate the findings of Zeqiri and Alija (2016) who found that the university tend to have culture of professionalism rather than having a culture of parochialism. The universities under studytend to have a culture of 
parochialism where employees are interested to be identified by their affailiation with their organization rather than being identified by their profession.

Universities using ICT tend to be more open and welcoming towards job seekers and new comers. The staff who were aware of basic use of ICT also looked cooperative to the new comers as per the findings of this research. These findings support the findings of Zeqiri and Alija (2016) as they found the same in their study that university's organizational culture tend to have orientation towards openness. The findings of this research also show a balance between loose and tight control in all three universities as there are few flexibiities while performing a task and there is strictness of procedures. The findings of this study are partially in line with the findings of the research conducted by Zeqiri and Alija (2016) who found that organizational culture of SEE university in Mecedonia is more flexible than having hard and tight control orientation. However, with regards to this research, it is found that there exists tight control orientation to some extent as well.

As far as the findings and results of this research are concerned, all the three university were found to have ICT-based work dimension towards being a pragmatic organization. Universities tend to be realisitic and pragmatic while the respondents think that all three universities have positive contribution to society using technology and devices for connecting with clients and pther stakeholders. These findings are in support of Zeqiri and Alija (2016) as they also concluded in the same way that SEE university's organizational culture show a pragmatic dimension as university staff thought that the university was contributing in betterment of society.The findings of this research also revealed that all three universities have similar dimensions of organizational culture as results of ANOVA show no significant differences in dimensions of organizational culture among universities. There were no significant differences of perceptions of faculty members, students and administrative staff regarding dimensions of organizational culture as ANOVA results revealed no difference of perceptions.

\section{Conclusion}

Culture is not created individually hence culture of any organization cannot be formed and created by individuals. Culture is formed collectively by accepting the values which play an import role in forming and developing university's culture. Cultures of studied universities reflect multiethnic, multi-cultural and multi-lingual approach. Universities are aimed to develop satisfaction 
among society about their contribution, better communication among administrative and faculty staff as well as among students too. Universities' culture is formed on three pillars i.e. beliefs, values and assumption and experiences of the members of the university also play an important role in forming universities' culture.

The analysis of data and results emerging from that analysis explicate that universities have a combination of Hofstede's dimensions of organizational culture, but the culture is more focused on achieving desired goals and results. The personal problems of the staff are overlooked which need to be considered by the organization being responsible for well-being and welfare of its employees. They need to be provided best possible internet facility and devices for staying in touch with all concerned. Organizational culture of universities is more parochial rather than professional as there is a gap of trust and cooperation among departments. It is also surfaced during the analysis that universities under study have openness in their system as newcomers are welcomed and they immediately get acclimatized to the working environment.

Organizational culture of these three universities was found rigid towards deadlines and time-periods whereas there are few flexibilities and relaxations in working conditions as well. The organizational culture of these universities is more realistic and pragmatic rather than being normative. Organizational culture of the universities is aimed to fulfillment of customers' (students') needs too. It is also revealed that in organizational cultures of these universities, results are considered more meaningful and important rather than the correct procedures. However, this research was limited in context and nature therefore increased sample size would add more validity to the results and would enable to analyze Hofstede's dimensions of organizational culture more closely and extensively.

\subsection{Recommendation}

In the light of findings and results of this research, recommendations are made for further implication and betterment of organizational culture of universities. The study recommends that personal needs, problems and issues of all the stakeholders including the management and staff using ICT be kept in consideration while demanding desirable results from them. Similarly, the study also recommends that organizations be updated on culture of collegiality and cooperation for effective and sustainable development in carrying out research using technology and devices. Cooperation and collaboration among various departments be ensured for smooth functioning of 
processes and procedures. All the academic managers especially middle managers (Deans, Head of Departments) be trained in using effective ICT tools for reliable and effective communication and information.

\section{References}

Adams, S. (2014). The Importance of Institutional Culture at A Technical College. Dissertation (2009). Retrieved from http://epublications.marquette.edu/dissertations_mu/337

Alvesson, M., \& Sveningsson, S. (2016). Changing organizational culture. New York: Routledge.

Ansah, M. O., Louw , L., \& Belso-Mart, J. (2019). The influence of national culture on organizational culture of multinational companies. Cogent Social Sciences, 5(1), 1-15.

Bartell, M. (2003). Internationalization of universities: A university culture-based framework. Higher Education, 45, 43-70.

Beytekin, O. F., Yalcinkaya, M. D., \& Karakoc, N. (2010). The Organizational Culture at The University. International Journal of Educational Researchers, 2(1), 1-13.

Beytekin, O. F., Yalçınkaya, M., \& Miray, D. (2010). The Organizational Culture At The University. The International Journal of Educational Researchers, 2(1), 1-13.

Blake, R. R., \& Mouton, J. S. (1964). The Managerial Grid. Housten, Texas: Gulf.

Burns, N., \& Grove, S. K. (1993). The practice of nursing research: Conduct, critique and Utilization. Philadelphia: Saunders.

Burns, T., \& Stalker, M. S. (1961). The Management of Innovation. London: Tavis- tock Publications.

Caliskan, A., \& Zhu, C. (2019). Organizational Culture Type in Turkish Universities using OCAI: Perceptions of Students. Journal of Education Culture and Society(2), 1-13.

Cameron, K. S., \& Freeman, S. J. (1991). Cultural congruence, strength and type: relationships to Effectiveness. Research in Organizational Change and Development, 5, 23-58.

Castro, M., \& Martins, N. (2010). The relationship between organisational climate and employee satisfaction in a South African information and technological organisation. South African Journal of Industrial Psychology, 36(1), 1-9.

Check, J., \& Schutt, R. K. (2012). Survey research. In J. Check, \& R. K. Schutt, Research Methods in Education (pp. 159-185). California: Thousand Oaks.

Coman, A., \& Bonciu, C. (2016). Organizational Culture in Higher Education: Learning from the Best. European Journal of Social Sciences Education and Research, 3(1), 135-145.

Creswell, J. W. (2014). Research design : qualitative, quantitative, and mixed methods approaches. SAGE Publications.

Ehrhart, M. G., Schneider, B., \& Macey, W. H. (2014). Organizational climate and culture: An introduction to theory, research and practice. New York, NY: Routledge.

Folch, M. T., \& Ion, G. (2009). Analysing the organizational culture of universities: Tow Models. Higher Education in Europe, 34(1), 143-154. 
Gall, M. D., Gall, J. P., \& Borg, W. R. (2007). Educational research: An introduction. Boston: Pearson.

Gutterman, A. S. (2015). Organizational Culture: A Guide for Growth-Oriented Entrepreneurs. Growth-Oriented Entrepreneurship Project .

Hofstede, G. (2011). National Cultures, Organizational Cultures, and the Role of Management. In Values and Ethics for the 21st Century (pp. 385-404). Madrid: BBVA.

Hofstede, G. (1997). Culture and organizations: Software of the mind. New York: McGraw-Hill.

Holden, N. (2002). Cross-Cultural Management - A Knowledge Management Perspective. $\therefore$ Harlow: Prentice Hall.

Holsapple, C. W., \& Joshi, K. D. (2001). Organizational knowledge resources. Decision Support Systems, 31(4), 39-54.

Hsu, M.-H., Tien, S.-W., Lin, H.-C., \& Chang, C.-M. (2015). Understanding the roles of cultural differences and socio-economic status in social media continuance intention. Information Technology and People, 28(1), 224-241.

Jameson, J. (2011). Changing Leadership Identities: the Role of Trust and Organisational Cultures in a Recessionary UK Higher Education Policy Context. London: London Metropolitan University.

Jones, M. L. (2007). Hofstede - culturally questionable? Oxford Business \& Economics Conference (pp. 1-9). Oxford: Oxford.

Kezar, A., \& Eckel, P. D. (2002). The effect of institutional culture on change strategies in higher education. The Journal of Higher Education, 73(4), 435-460.

Knudsen \& Loloma, 2007. The consequences of "culture's consequences". A critical approach to culture as collective programming applied to cross-cultural crews. . Vol . 8 (2), pp. (Journal of Maritime Affairs). $105-121$.

Knudsen, F., \& Froholdt, L. L. (2009). The consequences of “culture's consequences”. A critical approach to culture as collective programming applied to cross-cultural crews. Journal of Maritime Affairs, 8(2), 105 -121.

Kobylarek, A. (2017). Polish Humboldtian University in the face of paradigmatic change. UK: Cambridge Scholars Publishing.

Lu, V. N., Plewa, N. C., \& Ho, J. (2016). Managing governmental business relationships: The impact of organisational culture difference and compatibility. Australasian Marketing Journal, 24(2016), 93-100.

Lund, D. B. (2003). Organizational culture and job satisfaction. Journal of Business and Industrial Marketing, 18(3), 219-236.

Merkin, R. S. (2006). Uncertainty avoidance and facework: A test of the Hofstede model. International Journal of Intercultural Relations, 30(2006), 213-228.

Minkov, M., \& Hofstede, G. (2011). The evolution of Hofstede's doctrine. ross Cultural Management: An International Journal, 18(1), 10-20. 
Minkov, M., \& Hofstede, G. (2014). A replication of Hofstede's uncertainty avoidance dimension across nationally representative samples from Europe. International Journal of Cross Cultural Management, 14(2), 161-171.

Nazarian, A., Atkinson, P., \& Greaves, L. (2014). The relationship between national culture and organisational culture: Case of medium and large size organisations in Iran. The Macrotheme Review, 3(6), 66-78.

Niiniluoto , I. (1993). The aim and structure of applied research. Erkenntnis, 38, 1-21.

Peters, T., \& Waterman, R. (1982). In Search of Excellence. New York: Harper and Row.

Polit, D., \& Hungler, B. P. (1993). Nursing Research. Essentials of nursing research: Methods, appraisal, and utilization. Philadelphia: Lippincott .

Rashid, Z. A., Sambasivan, M., \& Johari, J. (2003). The influence of corporate culture and organisational commitment on performance. Journal of Management Development, 22(8), 708-728.

Salonda, L. L. (2008). Exploration of a university culture: A Papaua New Guinea case study. Melbourne: Victory University Of Technology.

Schabracq, M. J. (2007). Changing organizational culture: The change agent's guidebook. Chichester: Wiley.

Schein, E. (1999). The Corporate Culture Survival Guide. San Francisco: Jossey Bass.

Schein, E. (2004). Organizational Culture and Leaders. San Francisco: Jossy Bass.

Schein, E. H. (1994). Innovative cultures and organizations. In T. J. Allen, \& M. S. Scott Morton, Information Technology and the Corporation of the 1990's (pp. 125-146). New York: Oxford University Press.

Schein, E. H. (2010). Organizational Culture and Leadership (4th ed.). San Francisco: Jossy-Bass.

Scholten, M., \& Gomes, L. F. (2008). Silva, M. A. O. M., Correia, M. F.National culture and entrepreneur orientation between Brazil and Portugal. Organizational behavior and administeration, 14(1), 65-84.

Soares, A. M., Farhangmehr, M., \& Shoham, A. (2007). Hofstede's dimensions of culture in international marketing studies. Journal of Business Research, 60, 277-284.

Solomanidina, T. O. (2011). Organizational Culture of Companies. Moscow: INFRA-M.

Søndergaard, M. (1994). Geert Hofstede, Culture's Consequences: Comparing Values, Behaviours, Institutions, and Organizations Across Nations. Organization Studies, 15(3), 447-456.

Sudarsanam, S., \& Sorwar, G. (2010). Determinants of takeover premium in cash offers: An option pricing approach. Journal of Business Finance and Accounting, 37(5), 687-714.

Tierney, w. G., \& Lanford, M. (2017). Institutional Culture in Higher Education. In Encyclopedia of International Higher Education Systems and Institutions (pp. 1-9). Springer.

Vasyakin, B. S., Ivleva,, M. I., Pozharskaya, Y. L., \& Shcherbakova, O. I. (2016). A Study of the Organizational Culture at a Higher Education Institution (Case Study: Plekhanov Russian 
University of Economics (PRUE)). International Journal of Environmental \& Science Education, 11(10), 11515-11528.

Warter, L. (2019). The Impact of Organizational Culture in Higher Education. Case Study. Journal of Intercultural Management and Ethics(2), 173-200.

Wendt , H., Euwena, M. C., \& Emmerik, I. J. (2009). Leadership and team cohesiveness across Cultures. The Leadership Quarterly, 20(3), 358-370.

Williams, C. (2011). Research methods. 5(3), Journal of Business and Economics Research.

Zeqiri , J., \& Alija , S. (2016). The Organizational Culture Dimensions- The Case of Independent Private University in Mecedonia. Studia UBB Oeconomica, 61(3), 20-31. 